\title{
Incidence and case fatality of aneurysmal subarachnoid hemorrhage admitted to hospital between 2008 and 2014 in Norway
}

\author{
Lise R. Øie ${ }^{1,2}$ (1) Ole Solheim ${ }^{2,3} \cdot$ Paulina Majewska $^{3} \cdot$ Trond Nordseth $^{4} \cdot$ Tomm B. Müller $^{3} \cdot$ Sven M. Carlsen ${ }^{5,6}$. \\ Heidi Jensberg ${ }^{7} \cdot \varnothing_{\text {yvind Salvesen }}{ }^{8} \cdot$ Sasha Gulati $^{2,3}$
}

Received: 27 February 2020 / Accepted: 13 June 2020 / Published online: 30 June 2020

(C) The Author(s) 2020

\begin{abstract}
Background To provide age- and sex-specific incidence and case fatality rates for non-traumatic aneurysmal subarachnoid hemorrhage (aSAH) in Norway. We also studied time trends in incidence and case fatality, as well as predictors of death following aSAH. Methods A nationwide study using discharge data for patients admitted with aSAH between 2008 and 2014.

Results A total of 1732 patients with aSAH were included. The mean age was 60 years (SD 14) and 63\% were females. Crude annual incidence was 5.7 per 100,000 person-years (95\% CI 5.4-6.0) and was higher in females (6.3 per 100,000, 95\% CI 5.96.7) compared with males ( 4.9 per $100,000,95 \%$ CI 4.5-5.3). The annual decline in aSAH incidence was $3.2 \%$ per year $(p=$ 0.007). The cumulative proportions of fatalities at days 30,90 , and 1 year were $22 \%, 25 \%$, and $37 \%$, respectively. The 30 -day mortality rate did not change during the study period. Age (HR 0.7-2.2) and aneurysms in the posterior circulation (HR 1.7, 95\% CI 1.3-2.3, $p=0.001)$ were associated with higher 30-day case fatality following aSAH, while aneurysm repair (HR $0.2,95 \%$ CI $0.2-0.3, p<0.001)$ was associated with lower risk.

Conclusions The incidence of aSAH declined in Norway between 2008 and 2014. Case fatality following aSAH continues to be high, and the 30-day mortality during the study period was unchanged. Increasing age and aneurysms in the posterior circulation were associated with increased risk of death within 30 days following aSAH.
\end{abstract}

This article is part of the Topical Collection on Vascular Neurosurgery Aneurysm

\author{
Lise R. Øie \\ lise.oie@gmail.com \\ Ole Solheim \\ ole.solheim@ntnu.no \\ Paulina Majewska \\ plmajewska@gmail.com \\ Trond Nordseth \\ trond.nordseth@stolav.no \\ Tomm B. Müller \\ tomm.brostrup.muller@stolav.no \\ Sven M. Carlsen \\ sven.carlsen@ntnu.no \\ Heidi Jensberg \\ heidi.jensberg@helsedir.no \\ Øyvind Salvesen \\ oyvind.salvesen@ntnu.no \\ Sasha Gulati \\ sasha.gulati@ntnu.no
}

1 Department of Neurology, St. Olavs hospital, Trondheim University Hospital, 7006 Trondheim, Norway

2 Department of Neuromedicine and Movement Science, Faculty of Medicine and Health Sciences, Norwegian University of Science and Technology (NTNU), Trondheim, Norway

3 Department of Neurosurgery, St.Olavs hospital, Trondheim University Hospital, Trondheim, Norway

4 Department of Anesthesiology, St. Olavs hospital, Trondheim University Hospital, Trondheim, Norway

5 Department of Endocrinology, St. Olavs hospital, Trondheim University Hospital, Trondheim, Norway

6 Department of Clinical and Molecular Medicine, Norwegian University of Science and Technology (NTNU), Trondheim, Norway

7 Department of Health Registries, Directorate of Health, Trondheim, Norway

8 Department of Public Health and General Practice, Norwegian University of Science and Technology (NTNU), Trondheim, Norway 
Keywords Subarachnoid hemorrhage $\cdot$ Incidence $\cdot$ Case fatality $\cdot$ Survival

\section{Introduction}

Subarachnoid hemorrhage (SAH) from a ruptured aneurysm accounts for approximately $5 \%$ of all strokes and is a feared stroke subtype because of its high risk of poor functional outcome or death $[2,28]$. SAH may occur at all ages but is more common between the 4 th and 6 th decade of life. A ruptured intracranial aneurysm is responsible for $85 \%$ of SAH cases [22], but the pathophysiology of aneurysm formation and rupture is still not fully understood. The type and size of the aneurysm, as well as female gender and higher age seem to be associated with the risk of rupture [34]. Despite some genetic predisposition, intracranial aneurysms are usually not congenital but develop throughout the course of life [39]. Thus, established and modifiable risk factors, such as hypertension, smoking, and alcohol abuse, remain most important to address in the prevention of aneurysmal SAH (aSAH) [8].

The overall incidence of stroke has declined during the past decades, attributed to the reduction of the proportion of people who smoke and better detection and treatment of hypertension through health education and behavioral change programs $[1,2,6]$. Smoking and hypertension are also risk factors for aSAH, but the decline in the incidence of aSAH over the past decades is relatively modest compared with that for stroke in general [2]. It has been suggested that there might be a lag time between the reduction of stroke risk factors and the effect on aSAH incidence [6]. An overall incidence rate of approximately 9.1 per 100,000 person-years of aSAH was reported in a systematic review from 2007, with doubled rates in Japan and Finland and far lower rates in South and Central America [2]. A more recent systematic review found a global incidence of 6.1 (95\% CI 4.9-7.5) per 100,000 person-years [4]. Estimates of the incidence of true aSAH in the literature might be imprecise as many epidemiological studies on aSAH also include other causes, such as perimesencephalic SAH and arteriovenous malformations [17]. Another important reason for varying incidence rates in prior studies may be differences in study designs, i.e., different methods of case ascertainment, and different risk factor exposure and time periods [15]. Regarding survival after $\mathrm{aSAH}$, there is quite consistent data on declining trends for case fatality following $\mathrm{SAH}[21,23,26,28]$.

The current study was performed to investigate the national incidence and case fatality rates of aSAH in Norway for the years 2008 to 2014. The trends of annual aSAH rates were evaluated, as well as predictors of early death following aSAH.

\section{Methods}

\section{Data source}

\section{The Norwegian health care system}

Acute illness requiring hospital admission is treated free of charge by the Norwegian public health care system, and insurance policies do not influence the management of SAH. Only public hospitals provide inpatient health care to patients with SAH in Norway, and health authorities cover all inpatient treatment expenses.

\section{Norwegian patient registry}

The Norwegian patient registry (NPR) receives information regarding diagnoses from all patients receiving inpatient treatment by the Norwegian public specialist health care services. All discharge diagnoses are exclusively assigned by the physicians treating the patient and cannot later be altered. Based on NPR data we identified all patients hospitalized in Norway between 2008 and 2014 with a primary diagnosis of non-traumatic SAH (ICD-10 I60.0-I60.9). The validity of SAH diagnosis (ICD-10 I60.0-I60.9) in the NPR has been previously validated and found to have an overall confirmation rate of $95.3 \%$ [31, 40].

\section{The Norwegian prescription database}

The Norwegian prescription database contains information about all prescriptions dispensed in Norway since 2004 including the type of drug according to the Anatomical Therapeutic Chemical (ATC) classification. Diagnoses are registered for medications with reimbursement according to ICD-10 or version two of the International Classification of Primary Care [12]. Pharmacies are required to register each drug dispensed in the national prescription database, ensuring complete registration. Antithrombotic medications are only available at state-licensed pharmacies in Norway and dispensed to patients with a prescription from a physician. All filled prescriptions for oral formulations of antithrombotic medications were recorded including aspirin, dipyridamole, clopidogrel, prasugrel, ticagrelor, ticlodipine, warfarin, dabigatran, apixaban, rivaroxaban, dicumatrol, and phenylindandion. The use of oral antithrombotic drugs was registered as a dichotomous variable.

\section{Study population}

The number of inhabitants in Norway for each year during the study period was provided by Statistics Norway (Statistics Norway, Oslo, Norway). NPR identified patients aged 18 years 
or older with a first-time primary discharge code of nontraumatic SAH (I60.0-I60.9) within the same period. NPR and Norwegian Prescription database were linked on an individual level by a unique 11-digit personal identifier. Only patients with a valid personal identifier and a Norwegian residence permit were included in our study. Data from NPR were de-identified before provided to the study authors. The date of admission was used as the index date. Patients were followed until death or end of the study period, depending on what occurred first. In an attempt to decrease the likelihood of reporting inaccurate incidence rates for aSAH, we excluded SAH coded as nonaneurysmal SAH (I60.8-I60.9). The included aSAH were divided into hemorrhages of the 1) anterior circulation (I60.0-I60.3), 2) posterior circulation (I60.4-I60.5), and other intracranial locations (I60.6-I60.7). Due to Norwegian data privacy regulations, it was not possible to review electronic medical records nor diagnostic imaging of the included patients in this study. The study population was further screened for hypertension and diabetes mellitus in the NPR registry and the Norwegian Prescription Database [12]. Hypertension and diabetes mellitus were registered as dichotomous variables during the observation period.

\section{Data analysis}

Statistical analyses were performed with SPSS version 25.0 (IBM Corporation, NY, USA). Descriptive statistics were computed for patient characteristics.

\section{Calculations of incidence rates}

Incidence rates per 100,000 person-years for patients hospitalized with aSAH were calculated for the adult Norwegian population (3.6-4.0 million inhabitants during the study period), using data from Statistic Norway. Annual decline and confidence intervals for incidence rates were calculated based on the assumption of Poisson distribution.

\section{Calculation of case fatality}

The time at risk of dying was calculated as the difference between the day of admission and the date of death, and case fatality rates were computed at 30,90 and 365 days.

\section{Predictors of death}

We applied a Cox Proportional Hazard regression model to study factors associated with death at 30 days following aSAH. Variables from the univariable analyses with a $p$ value $<0.10$ were included in the multivariable model. Effect sizes were presented as a hazard ratio with $95 \%$ confidence intervals. $P$ values $<0.05$ were considered statistically significant. Survival analyses of patients with aSAH receiving aneurysm occlusion therapy were analyzed with log-rank tests and visualized using Kaplan-Meier curves.

\section{Results}

In total, 2685 patients identified by NPR were screened for inclusion. We excluded 953 patients based on our exclusion criteria (I60.8 $(n=188))$ and I60.9 $(n=765))$, and 1732 patients were included for further analyses.

\section{Patient characteristics}

Patient characteristics are presented in Table 1. Among 1732 included patients, $63 \%$ were women. The mean age of males was 58 years and for females 61 years (mean difference 2.7, $95 \%$ CI $1,3-4.0, p<0.001)$. The youngest patient was 18 years while the oldest was 104 years. Arterial hypertension was present in $25 \%$ of the included patients and diabetes mellitus among $8 \%$. At the time of aSAH, $21 \%$ used oral antithrombotic medication. The majority of the aneurysms (68\%) were located in the anterior circulation, compared with $9 \%$ in the posterior circulation and $21 \%$ in another intracranial location. In total, $64 \%$ of the patients underwent aneurysm repair procedures. Among those undergoing aneurysm repair, surgical clipping was performed in $44 \%$, endovascular occlusion in $59 \%$, and $3 \%$ underwent both procedures.

Table 1 Patient characteristics in 1732 patients with aSAH

\begin{tabular}{ll}
\hline Variable & Value \\
\hline Age, all, years, mean (SD) & $60(14)$ \\
Male, years, mean (SD) & $58(14)$ \\
Female, years, mean (SD) & $61(14)$ \\
Female, $n(\%)$ & $1087(63)$ \\
Oral antithrombotic drugs, $n(\%)$ & $360 / 1732(21)$ \\
Comorbidities & \\
Hypertension, $n(\%)$ & $429 / 1732(25)$ \\
Diabetes mellitus, $n(\%)$ & $133 / 1732(8)$ \\
Aneurysm location & \\
Anterior aneurysm (I60.0-I60.3), $n(\%)$ & $1199 / 1732(69)$ \\
Posterior aneurysm (I60.4-I60.5), n (\%) & $163 / 1732(9)$ \\
Other intracranial location (I60.6-I60.7), $n(\%)$ & $370 / 1732(21)$ \\
Aneurysm repair, $n(\%)$ & $1113 / 1732(64)$ \\
Clipping, $n(\%)$ & $489 / 1113(44)$ \\
Coiling, $n(\%)$ & $657 / 1113(59)$ \\
Coiling and clipping, $n(\%)$ & $33 / 1113(3)$ \\
CSF diversion procedures, $n(\%)$ & $944 / 1732(55)$ \\
External ventricular drainage, $n(\%)$ & $890 / 944(94)$ \\
Shunt, $n(\%)$ & $235 / 944(25)$ \\
Intracranial pressure monitoring, $n(\%)$ & $543 / 944(58)$ \\
\hline
\end{tabular}




\section{Incidence}

The crude annual incidence rate of aSAH between 2008 and 2014 in Norway was estimated to be 5.7 per 100,000 personyears (95\% CI 5.4-6.0). The incidence was higher in females (6.3 per $100,000,95 \%$ CI $5.9-6.7)$ than for males (4.9 per $100,000,95 \%$ CI $4.5-5.3)$. The incidence rates of aSAH by age and sex are presented in Fig. 1a and Table 2. The incidence rate increased with age until the sixth decade for both females and males, after which it reached a plateau before it started to decrease from the age of 70 . The female-to-male ratio remained relatively equal until the age of 45 years, after which the ratio increased with increasing age to the age of 60 years, and then remained relatively stable. In the study period the annual decline in aSAH incidence was $3.2 \%$ per year $(p=0.007)$ (Fig. 1b). In a separate analysis, we included all cases of SAH (I60.0-I60.9) and found a crude annual incidence of 8.8 per 100,000 person-years (CI 8.5-9.2).

\section{Case fatality}

Case fatality according to age is presented in Table 3. The cumulative proportions of fatalities at days 30,90 , and 1 year were $22 \%, 25 \%$, and $37 \%$, respectively. The 30 -day case fatality increased with age, from $27 \%$ in patients aged $<25$ years to $61 \%$ in those aged $>85$ years of age. The 30 -day case fatality incidence remained stable during the study period ( $0.1 \%$ annual increase, $p=0.98)$. Survival for patients with aSAH receiving aneurysm repair is presented in Fig. 2. The mean age of patients receiving surgery was 57 years (SD 12)
Fig. 1 a Incidence of aSAH by age and sex. b Annual incidence rate from 2008 to 2014
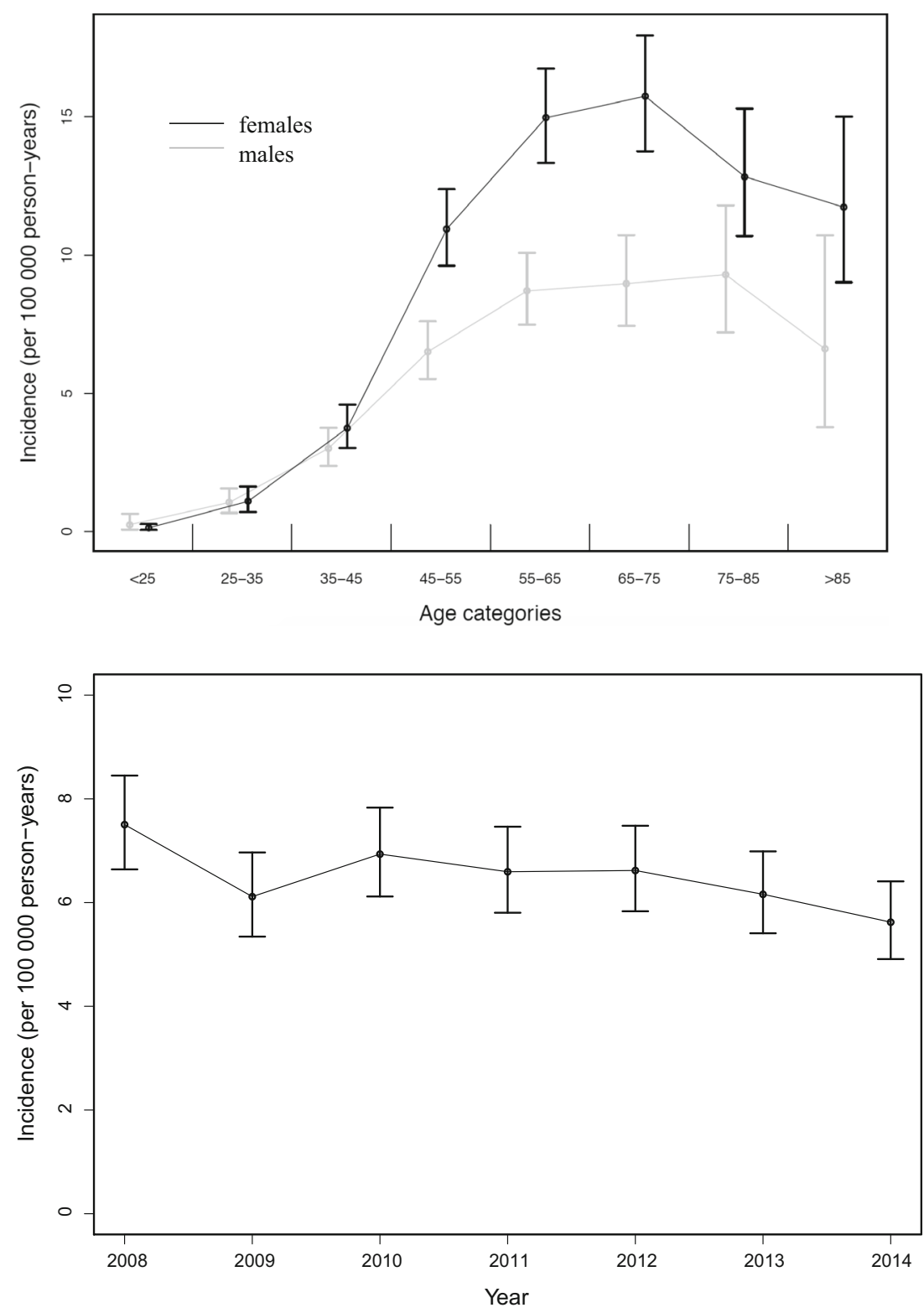
Table 2 Crude annual incidence rates of aSAH per 100,000 persons between 2008 and 2014 by sex and age group

\begin{tabular}{llll}
\hline $\begin{array}{l}\text { Age category } \\
\text { group }\end{array}$ & \multicolumn{3}{l}{ Incidence per 100,000 person-years $(95 \% \mathrm{CI})$} \\
\cline { 2 - 4 } & Female & Male & All \\
\hline $18-25$ & $0.1(0.1-0.3)$ & $0.3(0.1-0.6)$ & $0.2(0.1-0.3)$ \\
$25-34$ & $1.1(0.7-1.6)$ & $1.1(0.7-1.6)$ & $1.1(0.8-1.4)$ \\
$35-44$ & $3.7(3.0-4.6)$ & $3.0(2.4-3.8)$ & $3.4(2.9-3.9)$ \\
$45-54$ & $11.0(9.6-12.4)$ & $6.5(5.5-7.6)$ & $8.7(7.8-9.5)$ \\
$55-64$ & $15.0(13.3-16.8)$ & $8.7(7.5-10.1)$ & $11.8(10.8-12.9)$ \\
$65-74$ & $15.8(13.8-18.0)$ & $9.0(7.4-10.7)$ & $12.5(11.2-13.9)$ \\
$75-85$ & $12.8(10.7-15.3)$ & $9.3(7.2-11.8)$ & $11.3(9.8-13.0)$ \\
$>85$ & $11.7(9.0-15.0)$ & $2.9(1.7-4.7)$ & $10.1(8.0-12.6)$ \\
Total & $6.3(5.9-6.7)$ & $4.9(4.5-5.3)$ & $5.7(5.4-6.0)$ \\
\hline
\end{tabular}

and $64 \%$ were females. Elderly patients ( $>75$ years) had significantly higher case fatality after surgery compared with younger patients.

\section{Predictors of death}

In the univariable cox regression analysis the following variables were found to be significantly associated with death 30 days after the aSAH; increasing age (HR 0.4-2.5), hypertension (HR 1.4, 95\% CI 1.1-1.7), use of oral antithrombotic drugs at the time of hemorrhage (HR 1.8, 95\% CI 1.5-2.3, $p<0.001$ ), aneurysms in the posterior circulation (HR 1.6, 95\% CI 1.2-2.1, $p=0.003$ ), and aneurysm repair (HR $0.2,95 \%$ CI $0.1-0.2, p<0.001$ ) (Table 4). There were no gender differences with respect to survival after aSAH. In the multivariable cox analysis increasing age (HR 0.7-2.2), aneurysm in the posterior circulation (HR 1.7, 95\% CI 1.3-2.3, $p=0.001$ ), and aneurysm repair (HR 0.2, $95 \%$ CI $0.2-0.3, p<0.001)$ remained associated with death 30 days after aSAH.

\section{Discussion}

We found a crude annual incidence of aSAH in Norway between 2008 and 2014 of 5.7 per 100,000 person-years. The incidence increased with age until the middle of the sixth decade, after which it remained stable for some years before it started to decrease from the age of 70 . We found equal incidence rates for females and males until the age of 45 years, but thereafter we observed higher incidence rates of aSAH in females. We observed a decrease in the annual incidence rate of aSAH in Norway between 2008 and 2014. The case fatality of aSAH is still high, and we observed stable 30-day case fatality incidence during the study period. Increasing age and aneurysms in the posterior circulation were associated with higher 30-day case fatality, whereas aneurysm repair was associated with lower 30-day case fatality following aSAH.

The age and sex distributions found in our study are consistent with prior studies $[13,16,20]$. We found declining incidence in patients aged 70 years and older hospitalized with aSAH. Especially in the elderly, aSAH may be an unrecognized cause of death, and the real incidence of aneurysm rupture probably increases with age beyond 70 years. Unlike other types of strokes, there is a female preponderance for aSAH from the fifth decade of life. The reason for the frequently reported higher incidence of aSAH in females compared with males is unknown, but older age at aSAH event, hormonal factors (including use of hormone replacement therapy) [2, 8], anatomic differences in the circle of Willis [19], and increased vulnerability of smoking, and elevated systolic blood pressure in females compared with males [5, 18, 19] may in part explain the sex gap in aSAH incidence.

The crude incidence of aSAH has previously been estimated to be 9 per 100,000 person-years but varied considerably according to geographic location, age, and sex [2]. Comparisons between studies can be further complicated by different definitions of aSAH, study designs, and case finding procedures [15]. A more recent systematic review from 2010 found a global incidence of aSAH of 6.1 (95\% CI 4.9-7.5) per 100,000 person-years, which is more in line with the incidence found in our study [4]. Incidence rates between 7 and 12 per 100,000 person-years have been found in previous studies in Norway [20,36], Sweden [13, 29, 38], and the US [33]. All of these studies included all ICD-10 coded SAH (I60.0-I60.9) as endpoints, thus complicating comparisons with our study that only included aSAH coded as I60.0I60.7. When we included all cases of SAH (I60.0-I60.9) we

Table 3 Cumulative case fatality rates (CFR) of aSAH according to age group

\begin{tabular}{|c|c|c|c|c|c|c|c|c|c|}
\hline \multirow{2}{*}{$\begin{array}{l}\text { CFR } \\
(\%)\end{array}$} & \multicolumn{9}{|c|}{ Age category of patients (years) } \\
\hline & $\begin{array}{l}18-25 \\
(n=11)\end{array}$ & $\begin{array}{l}25-34 \\
(n=48)\end{array}$ & $\begin{array}{l}35-44 \\
(n=170)\end{array}$ & $\begin{array}{l}45-54 \\
(n=403)\end{array}$ & $\begin{array}{l}55-64 \\
(n=485)\end{array}$ & $\begin{array}{l}65-74 \\
(n=344)\end{array}$ & $\begin{array}{l}75-84 \\
(n=192)\end{array}$ & $\begin{array}{l}>85 \\
(n=79)\end{array}$ & $\begin{array}{l}\text { All ages } \\
(n=1732)\end{array}$ \\
\hline 30-day & 27 & 13 & 10 & 15 & 16 & 24 & 44 & 61 & 22 \\
\hline 90-day & 27 & 13 & 10 & 17 & 18 & 29 & 50 & 66 & 25 \\
\hline 365-day & 46 & 21 & 21 & 27 & 32 & 45 & 58 & 82 & 37 \\
\hline
\end{tabular}




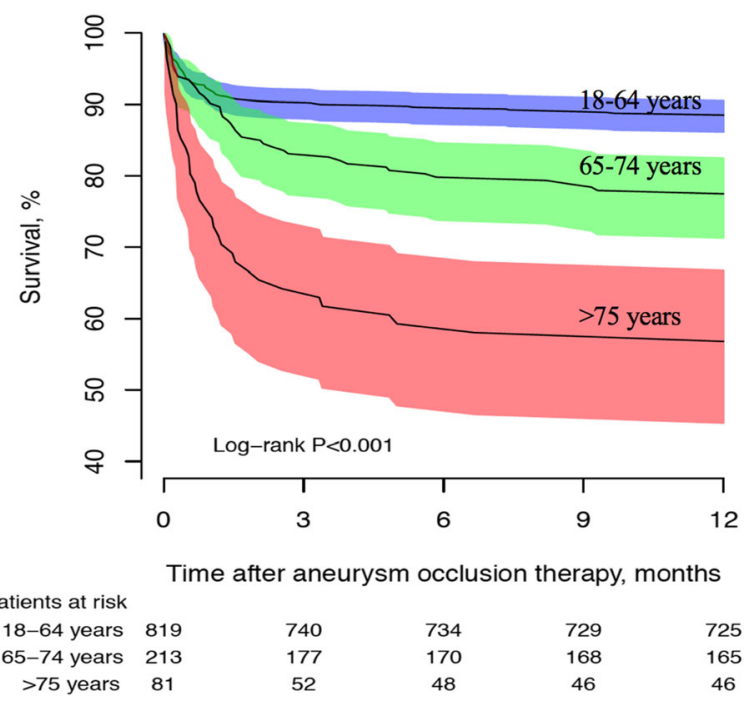

Fig. 2 Survival following aSAH in patients receiving aneurysm repair. Error bars represent $95 \%$ confidence intervals

found a crude annual incidence of 8.8 per 100,000 personyears. The low incidence rate found in the present study may depend on our strict criteria for the aSAH diagnosis; nevertheless, we believe that this is a more precise incidence of true aSAH. A Finish study, estimating aSAH coded as ICD-10 I60.0 to I60.6, is more in line with aSAH included in our study. They found a crude annual incidence rate between 6.2 and 10.0 per 100,000 persons between 1997 and 2007 [16].

We estimated an annual decline in aSAH during the study period of 3.2\% per year. An annual reduction of SAH incidence has been reported previously in two meta-analyses; the incidence of SAH decreased by $0.6 \%$ per year between 1950 and 2005[2], and by $1.7 \%$ per year between 1955 and 2014 [4]. Similar trends have been shown in previous epidemiological studies in Norway, [20] Sweden [13], and Finland [16]. However, a decline in aSAH incidence has not been observed in all countries. Stable regional incidence rates have been reported in the US (between 1988 and 2010) [23] and Australia (between 1998 and 2008) [17]. It has been estimated that with effective actions on common lifestyle factors at least half of all strokes may be prevented [7], and thus great effort has been put into reducing cardiovascular risk factors by health education and behavioral change programs. The relatively modest decline in the incidence of aSAH over the past decades compared with that for stroke in general has led to speculations that better control of risk factors is more influential in preventing ischemic stroke than in preventing aSAH [3, 32]. Another explanation might be that the effect of strategies to reduce smoking, one of the most significant risk factors for $\mathrm{aSAH}$, is more delayed in reducing aSAH incidence when compared with interventions that target other modifiable stroke risk factors [6]. Also, the effect of preventive interventions at different times of life might influence the risk of stroke differently, and thus the incidence of different stroke types.

Despite the increasing age of the general population, multiple population-based studies in several countries report a reduction in aSAH case fatality $[21,23,26,28,38]$. Our overall 30 -day case fatality rate of $22 \%$ is lower than the 30 -day CFR of $36 \%$ that was reported in Norway between 1984 and 2007 [36], and the 28-day CFR of 36.5\% and 31.7\% that was reported in Sweden between 1985 and 2000 and 1987-2002, respectively $[13,38]$. A systematic review published in 2009 (including studies from 1970 to 2008) reported an early case
Table 4 Cox regression analysis for survival at 30 days after aSAH

\begin{tabular}{|c|c|c|c|c|}
\hline \multirow[t]{2}{*}{ Variable } & \multicolumn{2}{|c|}{ Univariable regression } & \multicolumn{2}{|c|}{ Multivariable regression } \\
\hline & $\operatorname{HR}(95 \% \mathrm{CI})$ & $p$ value & $\operatorname{HR}(95 \% \mathrm{CI})$ & $p$ value \\
\hline \multicolumn{5}{|l|}{ Age (categorical) } \\
\hline $18-25$ years & Reference group & $<0.001$ & Reference group & $<0.001$ \\
\hline $25-34$ years & $0.4(0.1-1.7)$ & & $0.7(0.2-2.9)$ & \\
\hline $35-44$ years & $0.3(0.1-1.1)$ & & $0.6(0.2-2.2)$ & \\
\hline $45-54$ years & $0.5(0.2-1.6)$ & & $0.9(0.3-3.0)$ & \\
\hline $55-64$ years & $0.5(0.2-1.7)$ & & $1.0(0.3-3.2)$ & \\
\hline $65-74$ years & $0.8(0.3-2.6)$ & & $1.3(0.4-4.2)$ & \\
\hline $75-84$ years & $1.7(0.5-5.3)$ & & $2.0(0.6-6.3)$ & \\
\hline$>85$ years & $2.5(0.8-8.0)$ & & $2.2(0.7-7.1)$ & \\
\hline Sex (female) & $1.0(0.8-1.2)$ & 0.686 & - & - \\
\hline Hypertension & $1.4(1.1-1.7)$ & 0.003 & $1.0(0.8-1.2)$ & 0.769 \\
\hline Diabetes mellitus & $0.8(0.5-1.2)$ & 0.285 & - & - \\
\hline Oral antithrombotic medication & $1.8(1.5-2.3)$ & $<0.001$ & $0.9(0.7-1.2)$ & 0.485 \\
\hline Aneurysm location (posterior) & $1.6(1.2-2.1)$ & 0.003 & $1.7(1.3-2.3)$ & 0.001 \\
\hline Aneurysm repair (any) & $0.2(0.1-0.2)$ & $<0.001$ & $0.2(0.2-0.3)$ & $<0.001$ \\
\hline
\end{tabular}


fatality (21 days to 1 month) in low to middle-income countries of $43.9 \%$ and in high-income countries $30.0 \%$ [6]. Another systematic review from 2009 (including studies from 1972 to 2003) found that the 28-day CFR decreased by $0.8 \%$ per year [28]. Declining trends in population-based mortality rates were also reported in Scotland between 1986 and 2005 [24] and England between 1999 and 2010 [26]. In contrast to these studies, we found stable 30-day case fatality incidence during the study period. Existing data describing temporal trends in case fatality for aSAH are limited and conflicting, and comparison between studies is difficult as case finding, diagnostic methods, and management vary substantially between studies. The decreased case fatality observed in studies from the beginning of the year 2000 coincides with the introduction of improved investigative, diagnostic, and treatment strategies for aSAH $[10,25]$. We recruited patients with aSAH during a time period when both surgical clipping and endovascular coiling were well-established treatment options in all Norwegian neurosurgical centers, and this might explain both why case fatality is low and remained unchanged during the study period.

We found that older age and aneurysms in the posterior circulation significantly increased case fatality 30 days following aSAH, which is in agreement with previous studies [14, 27, 35]. While smoking, hypertension, and alcohol abuse are established modifiable risk factors for aSAH, the seemingly protective effects of hypercholesterolemia and diabetes in the etiology of aSAH are more uncertain [8, 18, 37]. The decline in incidence between 2008 and 2014 observed in the present study may possibly be attributed to changes in awareness, management, and prevalence of hypertension and diabetes mellitus. According to the Norwegian prescription databse, there was an increase in the number of patients on antihypertensive drugs from 157.1 to 164.4 per 1000 inhabitants in Norway between 2008 and 2014. For antidiabetic drugs, an increase from 29.2 to 33.2 per 1000 inhabitants was observed during the same period [30]. Hypertension and diabetes mellitus were not significantly associated with death 30 days after the hemorrhage in the present study. We found that one-fifth of patients suffering from aSAH were users of oral antithrombotic drugs, and that users of antithrombotic drugs were older than non-users. The use of oral antithrombotic medication was not significantly associated with death 30 days after aSAH. While most studies are consistent in reporting an increased risk of intracranial hemorrhage (including aSAH) in users of anticoagulant drugs compared with no therapy [9, 12], the results are more heterogeneous regarding the risk of aSAH associated with antiplatelet drugs $[9,11]$. We could not differentiate between antiplatelet and anticoagulant medications in our study. More than $60 \%$ of patients with aSAH underwent aneurysm repair, and occlusion therapy was associated with reduced risk of death 30 days after the hemorrhage. It has been reported previously that treatment of ruptured aneurysms in elderly patients (> 75 years) is feasible, may improve the outcome, and should be strongly considered in patients who are admitted to the hospital in a good condition [27]. Among patients receiving aneurysm repair, we found that elderly patients (> 75 years) had significantly higher case fatality compared with younger patients. Patients receiving surgery are generally younger than those not operated, and a decision is often based on expected better clinical outcome. It is still not settled how coiling compares with clipping in terms of outcomes. The choice of treatment modality depends on several factors including aneurysm location, size, and shape. Whether to clip or coil an aneurysm also depends on neurosurgeons' and interventional radiologists' experience and preferences. As aneurysms that are clipped often have different characteristics than those treated with coiling, in addition to the retrospective design, it is difficult to compare the effectiveness of the two treatment modalities in the present study.

\section{Strengths and limitations}

The strengths of this study include the large comprehensive nationwide sample collecting real-world data in a country with a free of charge public health care system that includes all inhabitants. Since the incidence of aSAH can vary between geographical areas, population-based incidence rates from a few hospitals or districts may be misleading. A population-based registry with complete coverage and continuously collected data on all Norwegian residents reduces referral, diagnostic, and information bias. Another strength is that patients were recruited during a time period when both surgical clipping and endovascular coiling were performed in all Norwegian neurosurgical centers. Brain CT scans and ICD-10 classification were also in routine use. The main limitation of this study is the lack of detailed information (i.e., radiological and clinical severity of the aSAH) as we were unable to access patients' hospital records and diagnostic imaging to validate the diagnoses. In an attempt to decrease the likelihood of reporting inaccurate incidence rates for aSAH, we excluded $\mathrm{SAH}$ coded as non-aneurysmal SAH (I60.8-I60.9), and as a consequence, our result may represent an underestimated incidence rate compared with other studies. Although positive predictive values of aSAH in NPR have been found to be high, studies using hospital discharge registries tend to overestimate the incidence rates [31]. We only used the primary diagnosis from NPR for the selection of aSAH episodes. Genuine episodes of aSAH may have had aSAH as a secondary diagnosis leading to underestimation. 
However, given the severity of symptoms for most instances of aSAH, this source of underestimation should be minimal. Also, the incidence rates reported might represent a slight overestimation as some episodes might be recurrent events that have been incorrectly assessed as first events. Given the low absolute risk of aSAH and the low risk of recurrence, this overestimation will be very small [13]. Another important limitation of our study is that cases dying unexpectedly outside of the hospital from aSAH are not included. The actual cause of death may be hard to determine for persons dying from aSAH before reaching the hospital, especially since the autopsy rate in Norway is the lowest among the Nordic countries [37], and an underestimation of the incidence of aSAH is likely. In previous studies, the share of patients with aSAH that die before arriving at the hospital has been estimated to be $8.3 \%$ (range $0.0-21$ ) [16, 28].

\section{Conclusions}

We report a 5.7 per 100,000 person-year crude incidence of aSAH in Norway between 2008 and 2014. Middle and old age females were more prone to aneurysmal rupture than males. In line with previous studies, we observed a decrease in incidence during the study period. Case fatality following aSAH was lower than previously reported, though still high, and we observed an unchanged case fatality rate of aSAH during the study period. Older age and aneurysms in the posterior circulation were associated with a higher risk of death 30 days following aSAH.

Funding Information Open Access funding provided by NTNU Norwegian University of Science and Technology (incl St. Olavs Hospital - Trondheim University Hospital).

\section{Compliance with ethical standards}

For this type of study, formal consent is not required.

Conflict of interest The authors declare that they have no conflict of interest.

Ethical approval Ethical approval was granted by the Regional Committee for Medical Research in Central Norway (2014/958).

Open Access This article is licensed under a Creative Commons Attribution 4.0 International License, which permits use, sharing, adaptation, distribution and reproduction in any medium or format, as long as you give appropriate credit to the original author(s) and the source, provide a link to the Creative Commons licence, and indicate if changes were made. The images or other third party material in this article are included in the article's Creative Commons licence, unless indicated otherwise in a credit line to the material. If material is not included in the article's Creative Commons licence and your intended use is not permitted by statutory regulation or exceeds the permitted use, you will need to obtain permission directly from the copyright holder. To view a copy of this licence, visit http://creativecommons.org/licenses/by/4.0/.

\section{References}

1. Carandang R, Seshadri S, Beiser A, Kelly-Hayes M, Kase CS, Kannel WB, Wolf PA (2006) Trends in incidence, lifetime risk, severity, and 30-day mortality of stroke over the past 50 years. JAMA 296:2939-2946. https://doi.org/10.1001/jama.296.24.2939

2. de Rooij NK, Linn FH, van der Plas JA, Algra A, Rinkel GJ (2007) Incidence of subarachnoid haemorrhage: a systematic review with emphasis on region, age, gender and time trends. J Neurol Neurosurg Psychiatry 78:1365-1372. https://doi.org/10.1136/ jnnp.2007.117655

3. Donnan GA, Hankey GJ, Davis SM (2010) Intracerebral haemorrhage: a need for more data and new research directions. Lancet Neurol 9:133-134. https://doi.org/10.1016/S1474-4422(10)700016

4. Etminan N, Chang HS, Hackenberg K, de Rooij NK, Vergouwen MDI, Rinkel GJE, Algra A (2019) Worldwide incidence of aneurysmal subarachnoid hemorrhage according to region, time period, blood pressure, and smoking prevalence in the population: a systematic review and meta-analysis. JAMA Neurol 76:588-597. https://doi.org/10.1001/jamaneurol.2019.0006

5. Feigin V, Parag V, Lawes CM, Rodgers A, Suh I, Woodward M, Jamrozik K, Ueshima H, Asia Pacific Cohort Studies C (2005) Smoking and elevated blood pressure are the most important risk factors for subarachnoid hemorrhage in the Asia-Pacific region: an overview of 26 cohorts involving 306,620 participants. Stroke 36: 1360-1365. https://doi.org/10.1161/01.STR.0000170710.95689. 41

6. Feigin VL, Lawes CM, Bennett DA, Barker-Collo SL, Parag V (2009) Worldwide stroke incidence and early case fatality reported in 56 population-based studies: a systematic review. Lancet Neurol 8:355-369. https://doi.org/10.1016/S1474-4422(09)70025-0

7. Feigin VL, Norrving B, Mensah GA (2017) Global burden of stroke. Circ Res 120:439-448. https://doi.org/10.1161/ CIRCRESAHA.116.308413

8. Feigin VL, Rinkel GJ, Lawes CM, Algra A, Bennett DA, van Gijn J, Anderson CS (2005) Risk factors for subarachnoid hemorrhage: an updated systematic review of epidemiological studies. Stroke 36: 2773-2780. https://doi.org/10.1161/01.STR.0000190838.02954. e8

9. Garcia-Rodriguez LA, Gaist D, Morton J, Cookson C, GonzalezPerez A (2013) Antithrombotic drugs and risk of hemorrhagic stroke in the general population. Neurology 81:566-574. https:// doi.org/10.1212/WNL.0b013e31829e6ffa

10. Gonzalez-Perez A, Gaist D, Wallander MA, McFeat G, GarciaRodriguez LA (2013) Mortality after hemorrhagic stroke: data from general practice (The Health Improvement Network). Neurology 81:559-565. https://doi.org/10.1212/WNL.0b013e31829e6eff

11. Gross BA, Rosalind Lai PM, Frerichs KU, Du R (2014) Aspirin and aneurysmal subarachnoid hemorrhage. World Neurosurg 82:11271130. https://doi.org/10.1016/j.wneu.2013.03.072

12. Gulati S, Solheim O, Carlsen SM, Oie LR, Jensberg H, Gulati AM, Madsbu MA, Giannadakis C, Jakola AS, Salvesen O (2018) Risk of intracranial hemorrhage (RICH) in users of oral antithrombotic drugs: nationwide pharmacoepidemiological study. PLoS One 13: e0202575. https://doi.org/10.1371/journal.pone.0202575

13. Koffijberg H, Buskens E, Granath F, Adami J, Ekbom A, Rinkel GJ, Blomqvist P (2008) Subarachnoid haemorrhage in Sweden 1987-2002: regional incidence and case fatality rates. J Neurol 
Neurosurg Psychiatry 79:294-299. https://doi.org/10.1136/jnnp. 2007.123901

14. Konczalla J, Brawanski N, Platz J, Senft C, Kashefiolasl S, Seifert V (2016) Aneurysm location as a prognostic outcome factor after subarachnoid hemorrhage (SAH) from ICA- aneurysms: implication for translational research - from bedside to bench?! World Neurosurg. https://doi.org/10.1016/j.wneu.2016.04.086

15. Korja M, Kaprio J (2016) Controversies in epidemiology of intracranial aneurysms and SAH. Nat Rev Neurol 12:50-55. https://doi. org/10.1038/nrneurol.2015.228

16. Korja M, Lehto H, Juvela S, Kaprio J (2016) Incidence of subarachnoid hemorrhage is decreasing together with decreasing smoking rates. Neurology 87:1118-1123. https://doi.org/10.1212/WNL. 0000000000003091

17. Lai L, Morgan MK (2012) Incidence of subarachnoid haemorrhage: an Australian national hospital morbidity database analysis. J Clin Neurosci 19:733-739. https://doi.org/10.1016/j.jocn.2011.09.001

18. Lindbohm JV, Kaprio J, Jousilahti P, Salomaa V, Korja M (2016) Sex, smoking, and risk for subarachnoid hemorrhage. Stroke 47: 1975-1981. https://doi.org/10.1161/STROKEAHA.116.012957

19. Lindekleiv H, Sandvei MS, Njolstad I, Lochen ML, Romundstad PR, Vatten L, Ingebrigtsen T, Vik A, Mathiesen EB (2011) Sex differences in risk factors for aneurysmal subarachnoid hemorrhage: a cohort study. Neurology 76:637-643. https://doi.org/10. 1212/WNL.0b013e31820c30d3

20. Lindekleiv HM, Njolstad I, Ingebrigtsen T, Mathiesen EB (2011) Incidence of aneurysmal subarachnoid hemorrhage in Norway, 1999-2007. Acta Neurol Scand 123:34-40. https://doi.org/10. 1111/j.1600-0404.2010.01336.x

21. Lovelock CE, Rinkel GJ, Rothwell PM (2010) Time trends in outcome of subarachnoid hemorrhage: population-based study and systematic review. Neurology 74:1494-1501. https://doi.org/10. 1212/WNL.0b013e3181dd42b3

22. Macdonald RL, Schweizer TA (2017) Spontaneous subarachnoid haemorrhage. Lancet 389:655-666. https://doi.org/10.1016/S01406736(16)30668-7

23. Mackey J, Khoury JC, Alwell K, Moomaw CJ, Kissela BM, Flaherty ML, Adeoye O, Woo D, Ferioli S, De Los Rios La Rosa F, Martini S, Khatri P, Broderick JP, Zuccarello M, Kleindorfer D (2016) Stable incidence but declining case-fatality rates of subarachnoid hemorrhage in a population. Neurology 87:2192-2197. https://doi.org/10.1212/WNL.0000000000003353

24. Macpherson KJ, Lewsey JD, Jhund PS, Gillies M, Chalmers JW, Redpath A, Briggs A, Walters M, Langhorne P, Capewell S, McMurray JJ, MacIntyre K (2011) Trends in incidence and in short term survival following a subarachnoid haemorrhage in Scotland, 1986-2005: a retrospective cohort study. BMC Neurol 11:38. https://doi.org/10.1186/1471-2377-11-38

25. Molyneux AJ, Kerr RS, Birks J, Ramzi N, Yarnold J, Sneade M, Rischmiller J, Collaborators I (2009) Risk of recurrent subarachnoid haemorrhage, death, or dependence and standardised mortality ratios after clipping or coiling of an intracranial aneurysm in the International Subarachnoid Aneurysm Trial (ISAT): long-term follow-up. Lancet Neurol 8:427-433. https://doi.org/10.1016/S14744422(09)70080-8

26. Mukhtar TK, Molyneux AJ, Hall N, Yeates DR, Goldacre R, Sneade M, Clarke A, Goldacre MJ (2016) The falling rates of hospital admission, case fatality, and population-based mortality for subarachnoid hemorrhage in England, 1999-2010. J Neurosurg 1-7. https://doi.org/10.3171/2015.5.jns142115
27. Nieuwkamp DJ, Rinkel GJ, Silva R, Greebe P, Schokking DA, Ferro JM (2006) Subarachnoid haemorrhage in patients $>$ or $=75$ years: clinical course, treatment and outcome. J Neurol Neurosurg Psychiatry 77:933-937. https://doi.org/10.1136/jnnp.2005.084350

28. Nieuwkamp DJ, Setz LE, Algra A, Linn FH, de Rooij NK, Rinkel GJ (2009) Changes in case fatality of aneurysmal subarachnoid haemorrhage over time, according to age, sex, and region: a metaanalysis. Lancet Neurol 8:635-642. https://doi.org/10.1016/S14744422(09)70126-7

29. Nilsson OG, Lindgren A, Stahl N, Brandt L, Saveland H (2000) Incidence of intracerebral and subarachnoid haemorrhage in southern Sweden. J Neurol Neurosurg Psychiatry 69:601-607

30. Norwegian Institute of Public Health Folkehelseinstituttet. http:// www.reseptregisteret.no/. Accessed 13 May 2020

31. Oie LR, Madsbu MA, Giannadakis C, Vorhaug A, Jensberg H, Salvesen O, Gulati S (2018) Validation of intracranial hemorrhage in the Norwegian Patient Registry. Brain Behav 8:e00900. https:// doi.org/10.1002/brb3.900

32. Price AJ, Wright FL, Green J, Balkwill A, Kan SW, Yang TO, Floud S, Kroll ME, Simpson R, Sudlow CLM, Beral V, Reeves GK (2018) Differences in risk factors for 3 types of stroke: UK prospective study and meta-analyses. Neurology 90:e298-e306. https://doi.org/10.1212/WNL.0000000000004856

33. Rincon F, Rossenwasser RH, Dumont A (2013) The epidemiology of admissions of nontraumatic subarachnoid hemorrhage in the United States. Neurosurgery 73:217-222; discussion 212-213. https://doi.org/10.1227/01.neu.0000430290.93304.33

34. Rinkel GJ, Djibuti M, Algra A, van Gijn J (1998) Prevalence and risk of rupture of intracranial aneurysms: a systematic review. Stroke 29:251-256

35. Rosengart AJ, Schultheiss KE, Tolentino J, Macdonald RL (2007) Prognostic factors for outcome in patients with aneurysmal subarachnoid hemorrhage. Stroke 38:2315-2321. https://doi.org/10. 1161/STROKEAHA.107.484360

36. Sandvei MS, Mathiesen EB, Vatten LJ, Muller TB, Lindekleiv H, Ingebrigtsen T, Njolstad I, Wilsgaard T, Lochen ML, Vik A, Romundstad PR (2011) Incidence and mortality of aneurysmal subarachnoid hemorrhage in two Norwegian cohorts, 1984-2007. Neurology 77:1833-1839. https://doi.org/10.1212/WNL. 0b013e3182377de3

37. Sandvei MS, Romundstad PR, Muller TB, Vatten L, Vik A (2009) Risk factors for aneurysmal subarachnoid hemorrhage in a prospective population study: the HUNT study in Norway. Stroke 40: 1958-1962. https://doi.org/10.1161/STROKEAHA.108.539544

38. Stegmayr B, Eriksson M, Asplund K (2004) Declining mortality from subarachnoid hemorrhage: changes in incidence and case fatality from 1985 through 2000. Stroke 35:2059-2063. https://doi. org/10.1161/01.STR.0000138451.07853.b6

39. van Gijn J, Kerr RS, Rinkel GJ (2007) Subarachnoid haemorrhage. Lancet 369:306-318. https://doi.org/10.1016/S0140-6736(07) 60153-6

40. Varmdal T, Bakken IJ, Janszky I, Wethal T, Ellekjaer H, Rohweder G, Fjaertoft H, Ebbing M, Bonaa KH (2016) Comparison of the validity of stroke diagnoses in a medical quality register and an administrative health register. Scand J Public Health 44:143-149. https://doi.org/10.1177/1403494815621641

Publisher's note Springer Nature remains neutral with regard to jurisdictional claims in published maps and institutional affiliations. 